\title{
The Impact of Shared Versus Individual Office Space On Therapist Appraisal of Their Work Environment
}

SHANE L. ROGERS, STEPHEN J. EDWARDS, REBECCA PERERA

Shane L Rogers, Edith Cowan University, School of Arts and Humanities, Perth, Western Australia, Australia

Stephen J. Edwards \& Rebecca Perera, Western Australia Health Department, Perth, Western

Australia, Australia

Correspondence: shane.rogers@ecu.edu.au

\begin{abstract}
Objective. The primary objective was to investigate the impact of shared versus individual office space on therapist appraisal of the work physical and social environment, and overall appraisal of working conditions.
\end{abstract}

Method. Therapists $(n=59)$ from Child and Adolescent Mental Health Services in Western Australia were surveyed about their appraisal of the social and physical work environment, in addition to their overall appraisal of working conditions.

Results. Compared to therapists with individual offices, therapists occupying shared office space reported lower appraisal of the work physical environment and lower overall appraisal of working conditions. No difference was found between groups for appraisal of the work social environment. Additionally, when statistically controlling for office space, both the appraisal of the social and physical environment made an independent contribution to the prediction of overall work satisfaction.

Conclusion. This research reveals that shared office space can negatively impact therapist appraisal of their work environment and reduce overall appraisal of working conditions. Additionally, results reveal the high importance of the physical environment for staff satisfaction in a mental health service.

Keywords: mental health services, job satisfaction, shared office space, therapists, physical environment, social environment

Acknowledgements: This research was funded by a grant from the Telethon Institute. The authors wish to thank the therapists that gave up some of their valuable time to participate in this study.

Competing interests: The authors declare no competing interests. 


\section{INTRODUCTION}

\section{Office space in healthcare}

The physical environment can impact service experience and well-being of both consumers and staff in healthcare settings. [1-6] This knowledge has influenced the construction of new facilities, and the refurbishment of old facilities, to be a more thoughtful process. [1] Organisations might assume that aspects of office design, commonly used in the corporate sector, are appropriate within the healthcare context. [7] It has been suggested that shared office space is one such design aspect that might be pursued in healthcare. [8] With the current trend towards integrated health care services (e.g., Integrated GP and mental health service) [9-12], and flexible work schedules [13], shared office space in Australian healthcare may become more prevalent. We use the term 'shared office space' to refer to offices that contain the primary workstation for multiple employees. The present study investigates how shared office space impacts appraisal of the work environment and job satisfaction for therapists working at community mental health clinics.

\section{Shared office space - Positives and negatives}

Research into shared office space has primarily been conducted in corporate contexts. Potential benefits of shared office space for administrators are reduced construction costs, and ease of accommodating new employees. $[14,15]$ The potential benefits for employees are increased communication, collaboration, and team solidarity from more frequent interaction among colleagues. [14, 15] However, there are also potential negative unintended consequences. Staff job satisfaction may decline due to a decreased sense of personal space, privacy, equity and increased distraction. [15-21]
Work environment - Physical and social aspects

In the organisational psychology literature, a distinction is made between physical and social aspects of the work environment. [2, 5, 22, 23] The physical environment constitutes the physical layout of the workplace, ambient noise levels, ventilation, and furnishings. [4] More specifically, Rashid and Zimring [2] make a distinction between indoor environmental variables (such as noise, temperature and air quality) and interior design variables (such as spatial layout and furnishings).

The work social environment constitutes an individual's perception of their organisational role [23-25], client and co-worker relationships $[23,24,26,27]$, and organisation-wide underlying beliefs and values. [24, 28] A distinction in terminology is made between organisational climate and organisational culture. $[29,30]$ Researchers using the term climate focus upon perceptions at a local level (e.g., relationships among co-workers), while researchers using the term culture focus on perceptions at a global level (e.g., beliefs about organisational values and support). [29, 30]

\section{The present study - Therapists occupying} distinct types of office space

The present study constitutes an exploratory investigation into perceptions of the physical and social work environment of therapists occupying either individual or shared office space. Throughout this article, the term therapist refers to staff employed to conduct therapy sessions at Child and Adolescent Mental Health Services (CAMHS) clinics. Considering prior literature [15-21], it was anticipated that therapists occupying shared office space would report lower appraisal of the physical work environment, and lower appraisal of their overall working conditions. 
Regarding social appraisal, shared office space might foster positive appraisal of workplace communication, collaboration, and facilitate a supportive workplace culture. [14] There is however also a potential for individuals to withdraw from interaction to cope with diminished personal space and privacy. [18] Additionally, close proximity might at times exacerbate conflict. [31] Considering these opposing forces, in the present study it was uncertain how, and if, office space would be associated with appraisal of the social environment.

A final aim of the present study was to predict overall work satisfaction from appraisal of both the social and physical work environment. There is a great deal of research linking both the work physical environment $[2,6,15,19,20$, $22,32-35]$ and social environment $[20,24,36-$ 42] to work outcomes such as employee satisfaction and stress. However studies that consider both aspects of the environment in tandem are rare $[15,20]$, particularly in the context of mental health organisations. [35] The present study therefore seeks to add to the research literature by exploring the relative influence the work physical and social environment has upon therapist appraisal of their overall working conditions.

\section{METHODS}

The sample and organisational context

The sample consisted of 59 therapists (69\% female) employed by Child and Adolescent Mental Health Services (CAMHS) across eight government funded community clinics in the metropolitan area of Western Australia. Some further participant characteristics are provided in Table 1. Participants were all qualified and employed to work in the delivery of psychological therapy and counselling to children, adolescents, and their families. This research received ethics approval from the
West Australian Health Department, audit number - 588QP.

Thirty-two of the surveyed therapists stated they occupied individual office space. The remaining 27 therapists stated they occupied shared office space and were required to book therapy space to see clients. The organisational context present at the time of the investigation presented a naturalistic experiment to contrast the experiences of therapists occupying shared office space versus those in more traditional individual offices. Mann Whitney tests were conducted to check whether participant characteristics differed across the individual and shared office groups. No significant differences were found for age $(z=.72, p=.47)$, years working in the industry $(z=.52, p=.61)$, or years working at CAMHS $(z=.49, p=.63)$. The groups were also not statistically different regarding gender composition $\left(\chi^{2}(1)=.59, p=.44\right)$.

Table 1. Participant characteristics split by office space.

\begin{tabular}{|c|c|c|}
\hline & $\begin{array}{l}\text { Individual office } \\
(\mathrm{n}=32)\end{array}$ & $\begin{array}{l}\text { Shared office } \\
(n=27)\end{array}$ \\
\hline Gender & $\begin{array}{l}20 \text { (female), } 6 \\
\text { (male), } 1 \\
\text { (missing) }\end{array}$ & $\begin{array}{l}21 \text { (female), } 10 \\
\text { (male), } 1 \\
\text { (missing) }\end{array}$ \\
\hline Age (years) & $\begin{array}{l}2(26-30), 6(31- \\
40), 10(41-50), 9 \\
(51-50), 5 \text { (older } \\
\text { than 61) }\end{array}$ & $\begin{array}{l}2(26-30), 4(31- \\
40), 12(41-50), \\
6(51-60), 2 \\
\text { (older than 61), } \\
1 \text { (missing) }\end{array}$ \\
\hline $\begin{array}{l}\text { Working in } \\
\text { the industry } \\
\text { (years) }\end{array}$ & $\begin{array}{l}2(2-5), 7(6-10) \text {, } \\
23 \text { (more than } \\
10)\end{array}$ & $\begin{array}{l}6(2-5), 2(6- \\
10), 19 \text { (more } \\
\text { than } 10)\end{array}$ \\
\hline $\begin{array}{l}\text { Working at } \\
\text { CAMHS } \\
\text { (years) }\end{array}$ & $\begin{array}{l}8 \text { (A year or less), } \\
8(2-5), 8(6-10), 8 \\
\text { (more than } 10)\end{array}$ & $\begin{array}{l}4 \text { (a year or } \\
\text { less), } 9(2-5), 5 \\
(6-10), 8 \text { (more } \\
\text { than 10) }\end{array}$ \\
\hline
\end{tabular}

\section{Survey instrument}

A brief survey was administered by the first author attending staff meetings at clinics. Survey measures for therapist appraisal of 
work social environment, physical environment, and overall appraisal of working conditions were required for our study. A practical constraint we faced was that the present research constituted a sub-part of a broader study, and survey space for items was very limited ${ }^{1}$. When consulting the literature we had difficulty locating a sufficiently brief measure of the perceived work social environment that encompassed aspects of both work climate and culture that was suitable for our purposes. [28] Therefore, we compiled our own brief list of questions to assess therapist perceptions of their work social environment. We also included a brief measure of our own devising for appraisal of the physical environment that we have published previously. [5] Some additional questions were included about noise, distraction, and work satisfaction. A couple of final open-ended questions were also included to obtain some qualitative data.

\section{Appraisal of the social environment}

The brief survey used in the present study included seven questions that aimed to measure appraisal of the work social environment. A 5-point response scale for these survey items was - (1) Not at all, (2) Somewhat, (3) Moderately, (4) Very, (5) Extremely. The survey items are provided below.

Working at CAMHS I feel:

- A sense of belonging.

- Appreciated.

- The work culture at CAMHS motivates me to be more productive.

- The work culture at CAMHS is supportive.

\footnotetext{
${ }^{1}$ The full final report from the broader study can be accessed at:

https://www.researchgate.net/publication/26121394
}

- There is a high degree of communication among colleagues.

- There is a high degree of collaboration among colleagues.

- If I have a problem/issue I will be listened to and it will be resolved.

A principal component factor analysis was carried out to confirm that the social environment survey items assessed a single factor. [43] Analysis revealed a single-factor solution to be the best fit, with only one eigenvalue above the commonly used criterion of 1 (eigenvalue $=4.67$ ). Inspection of the factor loadings shows the social environment items all loading on a single factor, see Table 2. The Cronbach's alpha value of this scale is .91. A composite social environment appraisal score was subsequently created by averaging across all items

Table 2. Factor loadings for the appraisal of social environment measure.

\begin{tabular}{lcc}
\hline Question item & $\begin{array}{c}\text { Factor 1: } \\
\text { Social } \\
\text { environment }\end{array}$ & Uniqueness \\
\hline Belong & 0.65 & 0.57 \\
Appreciated & 0.78 & 0.39 \\
Productive & 0.83 & 0.31 \\
Supportive & 0.90 & 0.19 \\
Communication & 0.87 & 0.25 \\
Collaboration & 0.83 & 0.31 \\
Resolution & 0.82 & 0.32 \\
\hline
\end{tabular}

\section{Work satisfaction}

A single survey item assessed appraisal of overall working conditions via the statement: 'Working at CAMHS I feel satisfied with working conditions'. This statement was

0_Staff_and_consumer_perceptions_of_the_physical _environment_in_Western_Australian_child_and_ad olescent_mental_health_services_CAMHS_2014 
included along with the social environment questions and was rated on the same 5-point response scale as those items. We recognise that a single item for measuring overall work appraisal is not ideal. However prior research has used simple questions to gauge overall satisfaction with the work environment in an effective manner that made us feel more confident with our own approach. [44]

\section{Appraisal of the office physical environment}

A measure of appraisal of the office physical environment was obtained via participants rating their office space on ten adjectives: Comfort, Safety, Space, Privacy, Noise, Toys/Books, Plants, Artwork, Lighting. The adjectives were rated on a 5-point scale: (1) Very Bad, (2) Bad, (3) OK, (4) Good, (5) Very Good. Again, we conducted a factor analysis finding evidence for a single dominant factor (eigenvalue $=6.32$ ). Factor loadings are presented in Table 3. The Cronbach's alpha of this scale is .95. A composite appraisal of the office physical space score was obtained by averaging across all items.

Table 3. Factor loadings for the appraisal of office physical environment measure.

\begin{tabular}{lcc}
\hline $\begin{array}{l}\text { Question } \\
\text { item }\end{array}$ & $\begin{array}{c}\text { Factor 1: } \\
\text { Physical } \\
\text { environment }\end{array}$ & Uniqueness \\
\hline Comfort & 0.94 & 0.11 \\
Safety & 0.82 & 0.32 \\
Space & 0.91 & 0.17 \\
Privacy & 0.91 & 0.17 \\
Noise & 0.89 & 0.20 \\
Toys/Books & 0.88 & 0.22 \\
Plants & 0.62 & 0.61 \\
Artwork & 0.80 & 0.36 \\
Lighting & 0.70 & 0.52 \\
\hline
\end{tabular}

\footnotetext{
2 The researcher who was physically present when administering the surveys clarified that this question was specifically referring to hearing other people
}

\section{Noise and distraction}

To further explore if shared office space was associated with greater noise and distraction, a few additional questions were included in the survey. Therapists were asked how often (during a typical working week) they speak with clients in a therapy room: (1) Never, (2) 13 times, (3) 4-10 times, (4) 11-20 times, (5) 2130 times, (6) more than 30 times. They were also asked 'When speaking with a client in a therapy room I have heard other people talking in the background': (1) Never, (2) Sometimes, (3) Often, (4) Always. A follow up question was 'When in a therapy room with a client if I hear other people talking in the background it...': (1) Doesn't make me uncomfortable, (2) Sometimes makes me uncomfortable, (3) Often makes me uncomfortable, (4) Always makes me uncomfortable. A set of three more questions about speaking with clients on the phone were asked using the same response scales as the therapy questions:

- During a typical working week how many times do you speak with clients on the phone?

- When speaking with a client over the phone I have heard other people talking in the background. ${ }^{2}$

- When on the phone with a client if I hear other people talking in the background it...

A final few questions focused on distraction. Therapists were asked 'Have you been distracted by background noise when...' -> On the phone with a client, in therapy room with client, working in your office space. These three items were rated on a 4-point scale: (1) Never, (2) Sometimes, (3) Often, (4) Always. 
Final open-ended questions

To gather some qualitative data to complement our quantitative results at the end of the survey two final items (with accompanying text box) were 'Below please provide any comments you have about the therapy rooms:', and 'Below please provide any comments you have about the office space'.

\section{RESULTS}

As described by Andy Field [45], throughout the results section we report $r$ as a measure of effect size for comparisons made between the individual and shared office groups. We use the guidelines of interpretation provided by Field [45] to assess whether effects observed are small $(r=.10)$, medium ( $r=.30)$, or large $(r$ $=.50)$. Participant responses to the openended questions were coded and sorted by first using key words in context, and then through a process of constant comparison, as described by Strauss and Corbin. [46]

The impact of office space on therapist appraisal of the work environment, and work satisfaction

On average the shared office therapists were found to have a substantially lower appraisal of office physical environment composite score ( $M=1.92, S D=0.73$ ) compared to the individual office therapists $(M=3.36, S D=$ $0.78), t(57)=7.29, p<.001, r=.69$. There was no statistically significant difference on the appraisal of social environment measure between the shared office therapists $(M=$ $2.66, S D=0.87)$ and individual office therapists $(M=3.06, S D=0.86), t(57)=1.74, p=.09, r=$ .22. Results therefore suggest that shared office space has a negative impact upon therapist perception of the physical environment but does not necessarily impact their appraisal of the social environment. The mean response to the overall satisfaction with working conditions item was substantially lower $(M=1.81, S D=0.83)$ for therapists occupying shared office space compared to those with individual offices $(M=2.87, S D=$ $0.83),(t(57)=4.44, p<.001, r=.51)$.

\section{Predicting overall work satisfaction from appraisal of the social and physical work environment}

A secondary aim was to predict work satisfaction from the appraisal of both the social and physical environment, while controlling for office space, and any other relevant clinician characteristics. No participant characteristic (i.e., age, gender, length of time working in industry, and length of time working with CAMHS) was found to significantly associate with work satisfaction so were not included in the regression as predictors (all ps $>.05$ ). The social (Pearson $r=$ $.58, p<.001$ ) and physical (Pearson $r=.56, p<$ $.001)$ environment composite scores were both correlated with work satisfaction, but not with each other. A multiple regression analysis was conducted entering overall appraisal of working conditions as the outcome variable, with the composite social and physical environment appraisal scores entered as predictors. To control for office situation (shared versus individual) this variable was included as an additional binary predictor. Overall, the predictors significantly accounted for $54 \%$ (Adjusted R-Square $=.54$ ) of the variance in overall appraisal of working conditions $(F(3,55)=24.03, p<.001)$. When controlling for office situation, appraisal of the work social environment (standardized beta= $.49, p<.001$ ) and work physical environment (standardised beta $=.38, p<.001$ ) both independently contributed to the prediction of overall appraisal of working conditions. Comparison of the standardised betas indicates that in the current study, when controlling for office space, appraisal of the 
work social environment made a slightly stronger contribution to the prediction of overall appraisal of working conditions compared with appraisal of the office physical environment.

\section{Results from additional survey questions - Noise and distraction}

As part of our survey we further explored some other relevant issues that may be affected by shared office space in a mental health organisation. Mental health services by their very nature involve a lot of sensitive conversations. We asked clinicians in our study how often they spoke to clients in therapy rooms or on the phone, how often they heard background noise during conversations with their clients, and how uncomfortable this made them feel. We also asked how often they experienced distraction due to noise when in their office, in a therapy room, or on the phone. Responses to these items are presented below for therapists occupying individual offices (Table 4) and shared offices (Table 5).

Table 4. Responses to noise questions by therapists occupying individual offices $(n=$ 32). Percentage scores are calculated excluding missing values.

\begin{tabular}{|c|c|}
\hline Question & Responses \\
\hline $\begin{array}{l}\text { How often speak with } \\
\text { clients in a therapy room } \\
\text { each week? }\end{array}$ & $\begin{array}{l}1-3 \text { times }=1(3 \%), 4-10 \\
\text { times }=12(38 \%), 11-20 \\
\text { times }=16(50 \%), 21-30 \\
\text { times }=2(6 \%), \text { More } \\
\text { than } 30 \text { times }=1(3 \%)\end{array}$ \\
\hline $\begin{array}{l}\text { How often hear others } \\
\text { talking in the background } \\
\text { when in therapy room } \\
\text { with client? }\end{array}$ & $\begin{array}{l}\text { Never }=9(28 \%), \\
\text { Sometimes }=16(50 \%), \\
\text { Often = } 6(19 \%) \text {, Always } \\
=1(3 \%)\end{array}$ \\
\hline $\begin{array}{l}\text { How often hearing others } \\
\text { talking in the background } \\
\text { when in therapy room } \\
\text { with client causes } \\
\text { discomfort for clinician? }\end{array}$ & $\begin{array}{l}\text { Doesn't }=3(12 \%), \\
\text { Sometimes = } 10(40 \%), \\
\text { Often = } 8(32 \%), \text { Always } \\
=4(16 \%), \text { missing = } 7\end{array}$ \\
\hline $\begin{array}{l}\text { How often speak with } \\
\text { clients on the phone each } \\
\text { week? }\end{array}$ & $\begin{array}{l}1-3 \text { times }=2(6 \%), 4-10 \\
\text { times }=14(44 \%), 11-20 \\
\text { times }=10(31 \%), 21-30 \\
\text { times }=1(3 \%), \text { More } \\
\text { than } 30 \text { times }=5(16 \%)\end{array}$ \\
\hline
\end{tabular}

\begin{tabular}{|c|c|}
\hline $\begin{array}{l}\text { How often hear others } \\
\text { talking in the background } \\
\text { when on the phone with } \\
\text { client? }\end{array}$ & $\begin{array}{l}\text { Never }=13(41 \%), \\
\text { Sometimes }=16(50 \%), \\
\text { Often }=2(6 \%), \text { Always } \\
=1(3 \%)\end{array}$ \\
\hline $\begin{array}{l}\text { How often hearing others } \\
\text { talking in the background } \\
\text { when on the phone with } \\
\text { client causes discomfort } \\
\text { for clinician? }\end{array}$ & $\begin{array}{l}\text { Doesn't = } 6(19 \%) \\
\text { Sometimes = } 6(19 \%) \text {, } \\
\text { Often = } 3(9 \%) \text {, Always } \\
=4(13 \%)\end{array}$ \\
\hline $\begin{array}{l}\text { How often distracted by } \\
\text { background noise when in } \\
\text { office? }\end{array}$ & $\begin{array}{l}\text { Never = } 11(34 \%) \text {, } \\
\text { Sometimes = } 14(44 \%), \\
\text { Often = } 6(19 \%) \text {, Always } \\
=1(3 \%)\end{array}$ \\
\hline $\begin{array}{l}\text { How often distracted by } \\
\text { background noise when in } \\
\text { therapy room? }\end{array}$ & $\begin{array}{l}\text { Never = } 11(34 \%), \\
\text { Sometimes = } 15(47 \%), \\
\text { Often = } 5(16 \%) \text {, Always } \\
=1(3 \%)\end{array}$ \\
\hline $\begin{array}{l}\text { How often distracted by } \\
\text { background noise when } \\
\text { on phone? }\end{array}$ & $\begin{array}{l}\text { Never }=10(31 \%), \\
\text { Sometimes }=17(53 \%), \\
\text { Often }=5(16 \%)\end{array}$ \\
\hline
\end{tabular}

Table 5. Responses to noise questions by therapists occupying shared offices $(n=27)$. Percentage scores are calculated excluding missing values.

\begin{tabular}{ll}
\hline \multicolumn{1}{c}{ Question } & \multicolumn{1}{c}{ Responses } \\
\hline $\begin{array}{l}\text { How often speak with } \\
\text { clients in a therapy room } \\
\text { each week? }\end{array}$ & $\begin{array}{l}\text { 1-3 times = 1 (4\%), 4-10 } \\
\text { times }=16(62 \%), 11-20\end{array}$ \\
& times = 8 (31\%), 21-30 \\
& $=1$
\end{tabular}




\begin{tabular}{ll} 
& $\begin{array}{l}\text { Often = 13 (48\%), } \\
\text { Always = 8 (30\%) }\end{array}$ \\
\hline $\begin{array}{ll}\text { How often distracted by } \\
\text { background noise when in }\end{array}$ & $\begin{array}{l}\text { Never }=11(34 \%), \\
\text { Sometimes }=15(47 \%), \\
\text { therapy room? }\end{array}$ \\
& $\begin{array}{l}\text { Often = } 5(16 \%), \text { Always } \\
=1(3 \%)\end{array}$ \\
\hline $\begin{array}{l}\text { How often distracted by } \\
\text { background noise when }\end{array}$ & Never = $1(4 \%)$, \\
on phone? & Sometimes = 6 (22\%), \\
& Often = 14 (52\%), \\
& Always = 6 (22\%) \\
\hline
\end{tabular}

The individual office group was compared with the shared office group on all variables using non-parametric Mann-Whitney tests. To minimise the chances of making a type 1 error (i.e., concluding there is an effect where there is none) we applied a Bonferroni correction to the $p$-value for determining statistical significance as described by Field. [45] We divided the number of comparisons (i.e., nine) by the standard $.05 p$ value so that only a $p$ value less than .006 would be deemed statistically significant. The individual office group did not statistically differ from the shared office group regarding the frequency of therapy sessions each week or frequency of phone conversations with clients each week ( $p s>.006$ ). Nor did the groups differ regarding how often individuals reported experiencing discomfort if they heard background noise during therapy or phone conversations ( $p s>$ .006).

The shared office group were found to report hearing others talking in the background substantially more often when interacting with clients in therapy rooms $(z=3.71, p<.006, r=$ $.48)$, and when on the phone with clients ( $z=$ $5.21, p<.006, r=.68)$. They also reported more frequent distraction when in the office $(z=$ 4.43, $p<.006, r=.58)$, in therapy rooms $(z=$ $3.00, p<.006, r=.39)$, and on the phone $(z=$ $4.64, p<.006, r=.60$ ).

Qualitative responses
Participants were given the opportunity to provide open-ended feedback regarding both the office and therapeutic space. The comments are provided as an appendix at the end of the article in tables 6 to 9. Overall, minor themes were reference to space issues (e.g., too few rooms), cleanliness issues, lacking resources, and air-conditioning issues. In Western Australia the summers tend to be very hot and air-conditioning problems can produce substantial discomfort. The main themes that emerged were about office space. Many therapists from the shared office group lamented the fact they had to share offices. While on the other hand there were multiple comments from the individual office group acknowledging they had an individual office and were appreciative of it. From both groups comments were made that provide further insight into why individual offices were preferable. Shared offices produce problems with noise/distraction, feeling 'crowded' and lacking personal space, with associated concerns about confidentiality. Some therapists reported experiencing tension/stress associated with having to book therapy rooms. In other comments concern was expressed about how the non-consistent environment for therapy sessions (i.e., changing rooms between sessions due to the booking system) might negatively impact the therapeutic process. Overall, the qualitative data was consistent with the quantitative findings, that clinicians much preferred having individual office/therapy space.

\section{DISCUSSION}

The main aim of the present study was to investigate the impact of working in shared office conditions on West Australian therapists working in community Child and Adolescent Mental Health Services (CAMHS). The therapists in shared office space reported lower appraisal of their physical work 
environment, and lower overall appraisal of working conditions. No significant effect of office space was found for appraisal of the work social environment. Results are consistent with prior research in other professions finding that shared offices can have negative consequences upon staff appraisal of the work environment [15-19], and shared offices do not necessarily have any social benefits for employees. [17, 20] An additional finding of the present study was that when statistically controlling for type of office space, both appraisal of the work social and physical environment made an independent contribution to the prediction of overall work satisfaction.

The therapists occupying shared offices reported hearing more frequent background noise when on the phone and in therapy with clients. They also reported experiencing more frequent distraction on the phone, in the office, and in therapy space. Open-ended responses provided by the therapists were consistent with the quantitative findings. Therapists occupying shared offices generally wrote negative comments about their office situation, for example: "The cramped, noisy work space makes it very difficult, if not impossible, to focus, to think clearly \& hinders productivity \& clear thinking \& not great for clinicians!". While therapists occupying individual offices generally appeared to be mindful of their fortunate situation, for example: "Have my own office very happy with this". Multiple therapists mentioned that shared office space has a negative impact by reducing privacy and is associated with distraction because of noise, for example: "Cramped. No privacy. Constant noise in background from other staff talking on phone or with colleagues making it difficult for me to concentrate on triage calls". These findings are consistent with prior literature reporting that noise/distraction issues and a diminished sense of privacy are commonly experienced in shared office contexts. [15-21] Research has suggested that these kind of issues are compounded in professions that require a high level of concentration. $[47,48]$ Working as a therapist involves a lot of report writing that benefits from an individual office as mentioned in a comment from a therapist with their own office: "My office space is small but functional and provides a safe space for clients. It also allows me to close my door at times to focus on report writing and other computer based tasks to ensure I'm utilising my time effectively and not disturbed by colleagues".

Studies have found that a comfortable and welcoming physical environment can positively influence client's perceptions of therapists [49-51], and increase the amount of self-disclosure by clients. [52-54] In the present study, some therapists were concerned about the impact that shared offices with bookable therapy rooms was having on the therapeutic process with their clients. For example, "No consistency across therapy rooms - which is definitely NOT ideal for children \& young people. I am used to being able to provide consistency of environment, space \& features/toys - which is important therapeutically. We cannot ensure the same room is available from session to session" and "It is essential that clients can develop a sense of security and safety by having the same therapy space every time and it is an environment that feels comfortable and welcoming, not sterile". Furthermore, one therapist described how a lack of control over the therapeutic space can limit the therapist's options when working with clients, for example: "I would much prefer clinicians have their own offices and use this for therapy - we don't just do therapy - we do psycho-education, link people to resources \& supports and we 
need to be able to access a computer/printer in many sessions. When you have your own office, you can have informative handouts at the ready to give out when the need arises". In the context of the present research, the negative impact of shared office space for therapists may therefore be compounded by a lack of control over the therapeutic space.

Therapist contact with clients occurs not just in the therapy rooms, but also via phone calls. Background noise with associated distraction during communication with clients is one issue. Another issue brought up by the therapists was concern about confidentiality when on the phone in shared office space, for example: "Nowhere to have a private \& confidential phone call with clients or other agencies regarding a client". It must also be noted there were also multiple comments provided that indicated confidentiality was an issue in some therapy rooms due to poor sound-proofing, for example: "Two therapy rooms are not soundproofed \& they are very cramped. It is possible to actually hear the conversation in the other room". A final issue that was mentioned in some comments was how shared bookable therapy rooms could hinder productivity and had potential to cause tension among staff. The service experiences busy periods just before and after school hours, where therapists are forced to compete for time slots. For example: "Competition for bookable therapy space causes frustration and impacts on team culture and results in less productivity due to limited opportunity to book consecutive clients", and "It is disruptive needing to compete for therapy space with other clinicians".

\section{Limitations and avenues for future research}

One limitation of the present study is that the study design makes it difficult to ascertain if the negative impact of the shared office space is primarily driven by a lack of personal space for conducting therapy, lack of personal space and privacy when working on case reports, logistical and social problems with the booking system, or a combination of these factors. Future research is needed to better understand and tease apart the extent that these factors can impact upon work appraisal of therapists (and for health practitioners in general). Furthermore, there are a multitude of other factors that might impact satisfaction with the work environment not encompassed by the present study. For example, the impact of different management practices [55, 56], and perceptions of the organisational ability to deliver quality care. [57] How these and other factors interact with the aspects identified in the present research are avenues for further inquiry.

Another limitation is that the measures used in the present study were newly created to meet a requirement to keep the survey as brief as possible. Future research with more established and comprehensive measures is required to better understand the relative importance of the work physical and social environment upon health practitioner satisfaction with their workplace. A final and important limitation is that we did not collect extensive information on therapist characteristics. Future research should collect more thorough background information on participants. For example, in the present study we did not collect information regarding therapist status as a full-time or part-time employee. Nor did we collect information to provide us with an idea regarding specifically where a therapist fit within the hierarchy of their clinic. Both factors could also influence perceptions of the environment and work satisfaction and should be controlled for in future research. 


\section{CONCLUSION}

An established literature exists on the demanding nature of mental health work and an increased prevalence of stress/burnout with increased staff turnover in mental health services compared with most other professions. [40, 58, 59] Findings of the present study suggest that shared office settings can diminish staff appraisal of their work environment, which might exacerbate the standard stressors associated with treating mentally unwell individuals, or act as a barrier for coping with stress. $[2,60]$ Therefore, short term money saved from utilising shared office space may cost more in the longer term due to staff dissatisfaction, turnover, and decreased quality of service delivery. [8, 47, 48, 61-64] As summarized by one therapist in the present study: "Shared office space has placed our therapeutic work into the category of desk office workers rather than understanding the fundamentals of therapy. It is all about saving dollars rather than the bigger picture of assisting clients to change their behaviour, emotions, etc". Finally, our study of therapists complements other recently published work that has provided evidence to suggest a relationship exists between client appraisal of the physical environment and their reported emotional experience in a mental health service environment. [5]

\section{References}

1. Ulrich RS, Zimring C, Zhu X, DuBose J, Joseph A. A review of the research literature on evidence-based healthcare design. Health Environments Research and Design Journal. 2008;3(1):61-125.

2.

Rashid M, Zimring C. A review of the empirical literature on the relationships between indoor environment and stress in health care and office settings: problems and prospects of sharing evidence. Environment and Behavior. 2008;20(2):151-90.

3. Becker F, Parsons KS. Hospital facilities and the role of evidence-based design. Journal of Facilities Management. 2007;5(4):263-74.

4. Huisman ERCM, Morales E, van Hoof J, Kort HSM Healing environment: A review of the impact of the physical environmental factors on users. Building and Environment. 2012;58(70-80).

5. Rogers SL, Edwards SJ, Hudman P, Perera R. The importance of the physical environment for child and adolescent mental health services. Asia Pacific Journal of Health Management. 2016;11(1):33-43.

6. Rechel B, Buchan J, McKee M. The impact of health facilities on healthcare workers' well-being and performance. International Journal of Nursing Studies. 2009;46:1025-34.

7. Gunn R, Davis MM, Hall J, Heintzman J, Muench J, Smeds B, et al. Designing clinical space for the delivery of integrated behavioral health and primary care. Journal of the American Board of Family Medicine. 2015;28(Supplement 1):S52-S62.
8. Oommen VG, Knowles M, Zhao I. Should health service managers embrace open plan work environments? A review. Asia Pacific Journal of Health Management. 2008;3(2):37-43.

9. Lawn S, Lloyd A, King A, Sweet L, Gum L. Integration of primary health services: being put together does not mean they will work together. BMC research notes. $2014 ; 7(1): 1$.

10. Callaly T, Von Treuer K, Dodd S, Berk M. Mental health services for young people - the challenge of integrating services. Acta Neuropsychiatrica. 2010;22(03):158-60.

11. Allen C, Stevens S. Health service integration: a case study in change management. Australian Health Review. 2007;31(2):267-75

12. Booker C, Turbutt A, Fox R. Model of care for a changing healthcare system: are there foundational pillars for design? Australian Health Review. 2016;40:136-40.

13. May K, McAlinde F, Splawa-Neyman M, O'Rourke M, Sturgess T. Flexible, capable, adaptable: A dynamic allied health workforce. Asia Pacific Journal of Health Management. 2017;12(1):25-35.

14. Zagenczyk TJ, Murrell AJ, Gibney R. Effects of the physical work environment on the creation of individual and group level social capital. International Journal of Organizational Analysis. 2008;15(2):119-35.

15. Davis MC, Leach DJ, Clegg CW. Chapter 6: The physical environment of the office: Contemporary 
and emerging issues. International Review of Industrial and Organizational Psychology. 2011;26:193-237. Danielsson CB, Bodin L. Difference in satisfaction with office environment among employees in different office types. Journal of Architectural and Planning Research. 2009;26(3):241-57.

17. Pejtersen J, Allermann L, Kristensen TS, Poulsen OM. Indoor climate, psychosocial work environment and symptoms in open-plan offices. Indoor Air. 2006;16:392-401.

18. De Croon E, Sluiter J, Kuijer PP, Frings-Dresen M. The effect of office concepts on worker health and performance: a systematic review of the literature. Ergonomics. 2005;48(2):119-34.

19. Herbig B, Schneider A, Nowak D. Does office space occupation matter? The role of the number of persons per encolsed office space, psychosocial work characteristics, and environmental satisfaction in the physical and mental health of employees. Indoor Air. 2016;26:755-67.

20. Brennan A, Chugh JS, Kline T. Traditional versus open office design: A longitudinal field study. Environment and Behavior. 2002;34(279-299).

21. Morrison RL, Macky KA. The demands and resources arising from shared office spaces. Applied Ergonomics. 2017;60:103-15.

22. Kim SE. Physical workplace as a strategic asset for improving performance in public organizations. Administration \& Society. 2014;46(5):496-518.

23. Weinberg A, Creed F. Stress and psychiatric disorder in healthcare professionals and hospital staff. The Lancet. 2000;355(9203):533-7.

24. Lu H, Barriball KL, Zhang X, While AE. Job satisfaction among hospital nurses revisted: A systematic review. International Journal of Nursing Studies. 2012;49:1017-38.

25. Acker GM. The effect of organisational conditions (role conflict, role ambiguity, opportunities for professional development, and social support) on job satisfaction and intention to leave among social workers in mental health care. Community Mental Health Journal. 2004;40(1):65-73.

26. Schauer C, Everett A, del Vecchio P. Promoting the value and practice of shared decision-making in mental health care. Psychiatric Rehabilitation Journal. 2007;31(1):54-61.

27. Ackerman SJ, Hilsneroth MJ. A review of therapist characteristics and techniques positively impacting the therapeutic alliance. Clinical Psychology Review. 2003;23(1):1-33.

28. Scott T, Mannion R, Davies H, Marshall M. The quantitative measurement of organizational culture in health care: A review of the available instruments. Health Services Research. 2003;38(3):923-45.
29. Sleutel M. Climate, culture, context, or work environment?: Organizational factors that influence nursing practice. The Journal of Nursing Administration. 2000;30(2):53-8.

30. Denison DR. What is the difference between organizational culture and organizational climte? A native's point of view on a decade of paradigm wars. The Academy of Management Review. 1996;21(3):619-54.

31. Oldham GR, Rotchford NL. Relationships between office characteristics and employee reactions: $A$ study of the physical environment. Administrative Science Quarterly. 1983:542-56.

32. Frontczak M, Schiavon S, Goins J, Arens E, Zhang H, Wargocki P. Quantitative relationships between occupant satisfaction and satisfaction aspects of indoor environmental quality and building design. Indoor Air. 2012;22(2):119-31.

33. Ulrich RS. Effects of interior design on wellness: theory and recent scientific research. Journal of Health Care Interior Design. 1991;3(1):97-109.

34. Folkins C, O-Reilly III C, Roberts K, Miller S. Physical environment and job satisfaction in a community mental health center. Community Mental Health Journal. 1977;13(1):24-30.

35. Connellan K, Gaardboe M, Riggs D, Due C, Reinschmidt A, Mustillo L. Stressed spaces: Mental health and architecture. Health Environments Research and Design Journal. 2013;6(4):127-268.

36. Parker CP, Baltes BB, Young SA, Huff JW, Altmann RA, Lacost HA, et al. Relationships between psychological climate perceptions and work outcomes: a meta-analytic review. Journal of Organizational Behavior. 2003;24:389-416.

37. Taylor SE. Fostering a supportive environment at work. The Psychologist-Manager Journal. 2008;11:265-83.

38. Aarons GA, Sawitzky AC. Organisational climate partially mediates the effect of culture on work attitudes and staff turnover in mental health services. Administration and Policy in Mental Health Services Research. 2006;33(3):289-301.

39. Burke RJ, Oberklaid F, Burgess Z. Organizational values, work experiences, and satisfactions among Australian psychologists. I nternational Journal of Organizational Analysis. 2003;11(2):12335.

40. Littlewood S, Case P, Gater R, Lindsey C Recruitment, retention, satisfaction and stress in child and adolescent psychiatrists. Psychiatric Bulletin. 2003;27:61-7.

41. Bacapanos E, Edgar S. Identifying the factors that affect the job satisfaction of early career Notre Dame graduate physiotherapists. Australian Health Review. 2016;40:538-43. 
42. Joiner TA, Bartram T. How empowerment and social support affect Australian nurses' work stressors. Australian Health Review. 2004;28(1):56-64.

43. Acock A. A gentle introduction to Stata. 4th ed. College Station, Texas: Stata Press; 2014.

44. Veitch JA, Charles KE, Farley KMJ, Newsham GR. A model of satisfaction with open-plan office conditions: COPE field findings. Journal of Environmental Psychology. 2007;27:177-89.

45. Field A. Discovering Statistics Using SPSS. 3rd ed. London: SAGE Publications; 2009.

46. Strauss A, Corbin J. Basics of Qualitative Research: Grounded Theory Procedures and Techniques. Newbury Park, CA: SAGE Publications; 1990.

47. Seddigh A, Berntson E, Danielsson CB, Westerlund H. Concentration requirements modify the effect of office type on indicators of health and performance. Journal of Environmental Psychology. 2014;38:16774.

48. Seddigh A, Stenfors C, Berntsson E, Baath R, Sikstrom S, Westerlund $\mathrm{H}$. The association between office design and perfomance on demanding cognitive tasks. Journal of Environmental Psychology. 2015;42:172-81.

49. Nasar JL, Devlin AS. Impressions of psychotherapists offices. Journal of Counseling Psychology. 2011;58(3):310-20.

50. Devlin AS, Nasar JL. Impressions of psychotherapists offices: Do therapists and clients agree? Professiona Psychology: Research \& Practice. 2012;43:118-22.

51. Devlin AS, Nasar JL, Cubukcu E. Students' impressions of psychotherapists' offices: Crosscultural comparisons. Environment and Behavior. 2013:1-26.

52. Miwa Y, Hanyu K. The effects of interior design on communication and impressions of a counselor in a counseling room. Environment and Behavior. 2006;38:484-502.

53. Chaikin AL, Derlega VJ, Miller SJ. Effects of room environment on self-disclosure in a counseling analogue. Journal of Counseling Psychology. 1976;23(5):479-81.
54. Okken V, van Rompay T, Pruyn A. Room to move: On spatial constraints and self-disclosure during intimate conversations. Environment and Behavior. 2012;45(6):737-60

55. Nielson B, Ward P. Corporate management and clinical autonomy: The ethical dilemma in mental health. Australian Health Review. 1997;20(2):83-92.

56. Wilson NA. Factors that affect job satisfaction and intention to leave of allied health professionals in a metropolitan hospital. Australian Health Review. 2015;39(3):290-4.

57. Leggat SG, Bartram T, Casimir G, Stanton P. Nurse perceptions of the quality of patient care: Confirming the importance of empowerment and job satisfaction. Health Care Management Review. 2010;35(4):355-64.

58. Hannigan B, Edwards D, Burnard P. Stress and stress management in clinical psychology: Findings from a systematic review. Journal of Mental Health. 2004;13(3):235-45.

59. Coates D, Howe D. Combatting staff burnout in mental health: Key managerial and leadership tasks that are fundamental to staff wellbeing and retention. Asia Pacific Journal of Health Management. 2015;10(2):24-32.

60. Laurence GA, Fried Y, Slowik LH. "My space": A moderated mediation model of the effect of architectural and experienced privacy and workplace personalization on emotional exhaustion at work. Journal of Environmental Psychology. 2013;36:144-52.

61. van Ree $\mathrm{H}$. The added value of office accommodation to organisational performance. Work Study. 2002;51(6/7):357-63

62. Appel-Meulenbroek R, Groenen P, Janssen I. An enduser's perspective on activity-based office concepts. Journal of Corporate Real Estate. 2011;13(2):122-35.

63. Danielsson CB, Chungkham HS, Wulff C, Westerlund $\mathrm{H}$. Office design's impact on sick leave rates. Ergonomics. 2014;57(2):139-47.

64. Maher A, von Hippel C. Individual differences in employee reactions to open-plan offices. Journal of Environmental Psychology. 2005;25:219-29.

Table 6. Comments provided by therapists occupying individual offices, about office space.

OSH Field day - Bad chairs. Bad lighting. Desks too low. PC screen too low. Carpets dirty. Air con dirty. Air ducts dirty. Office space limited, need to review use of rooms. Limited funding to support this change. 14 staff - only two shared rooms. Need additional computer terminals \& desks for when we have additional staff (e.g., registrars \& students \& increased, PTE). Also only $3 x$ therapy space, which 5 clinicians use regularly, so on occasion no space to see clients. Only females share office rooms, all male have individual space/office - inequitable gender balance: challenging issue to implement change.

Office space - dark hallways - big heavy doors that don't have windows in them - possibly be safety issues.

We could do with a makeover of our 1960s building. Paint peeling - external walls makes this an uninviting building to our clients Need more space \& resources 
Have my own office very happy with this

Individual \& staff V. satisfied with this

Adequate space and comfort

Would like better chair, and ergometric set up

Equipment needs to be upgraded urgently

My office space is small but functional and provides a safe space for clients. It also allows me to close my door at times

to focus on report writing and other computer based tasks to ensure I'm utilising my time effectively and not disturbed

by colleagues

The air conditioning is very bad

Important to have a dedicated office space for each clinician. The client/family have to be seen in a safe/secure,

predictable environment - best if in the same space each time.

Appears to be a lack of office/therapy space - have had to use a small room next to waiting room and conference room very difficult for both admin and therapy (i.e., noise level and confidentiality)

For me MUCH better office space than previous clinic

My office space is suitable for the work I do with individuals and their families as well as all the admin work that I am

expected to do

More up-to-date computers would be useful.

\section{Table 7. Comments provided by therapists occupying individual offices, about therapy space.}

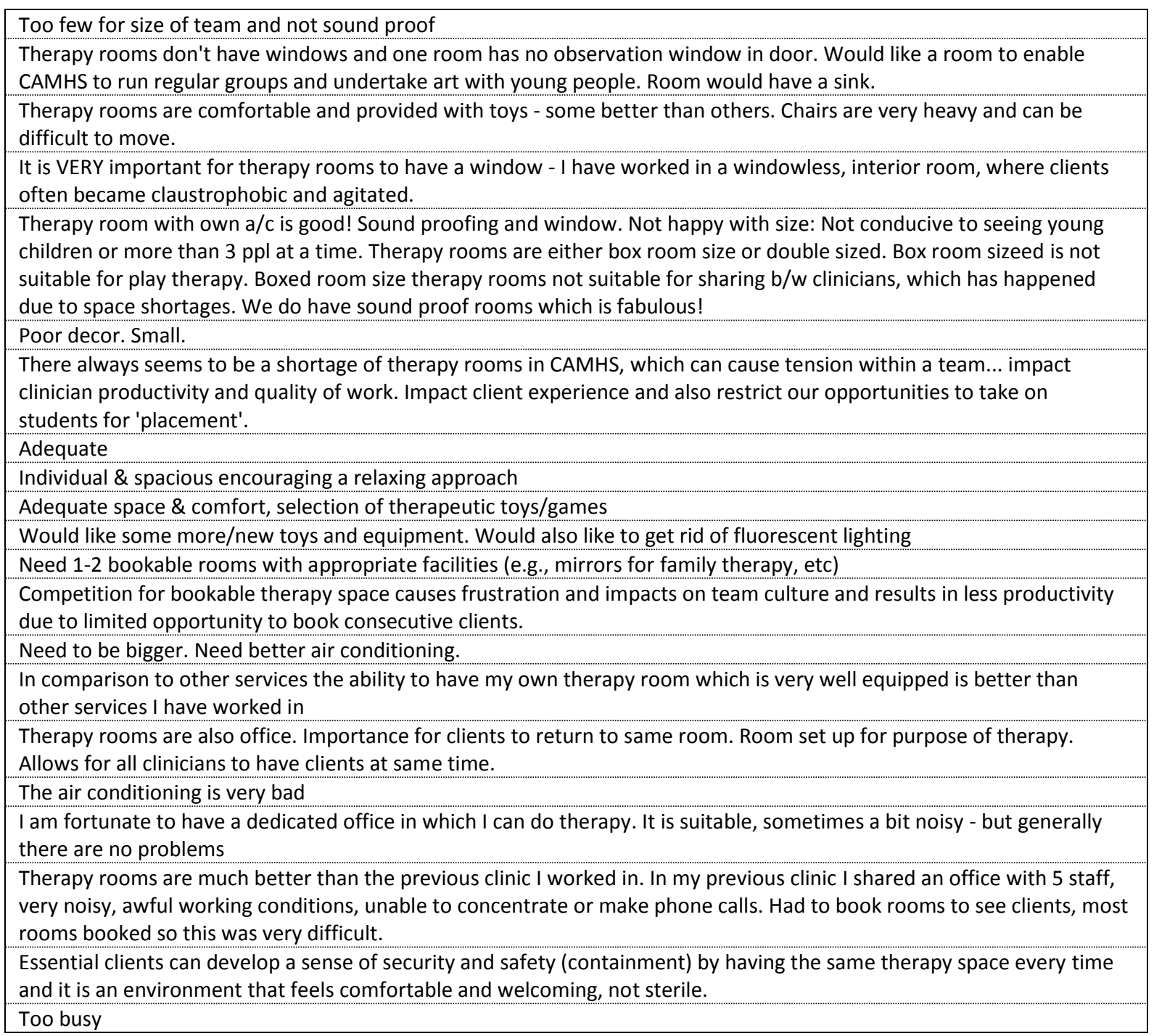


Important to utilise same therapeutic space with clients. At another clinic I didn't have my own room - bookable... and this detracted from therapy not having the consistency \& same room space \& toys. There were difficulties booking clients for urgent appointments.

\section{Table 8. Comments provided by therapists occupying shared offices, about office space.}

Office space - we have had lots of changes. My resources and materials are in dis-array due to several room changes \& no time to sort out. I would much much prefer clinicians have their own offices and use this for therapy - we don't just do therapy - we do psycho-education, link people to resources \& supports and we need to be able to access a computer/printer in many sessions. When you have your own office you can have informative handouts at the ready to give out when the need arises. We have less time to make do with worse facilities which takes more time. I am happy with my workplace, however share the room with 3 other people. We have had ongoing problems with airconditioning resulting in the use of heating in winter and hot in summer resulting in sleepiness. I have a work colleague who doesn't understand personal space and shares her cares with anyone in the room regardless of cues given to her. We are privy to all telephone calls made by triage officer and we have resorted to ear plugs to complete reports and formulations and check file information.

Nowhere to have a private \& confidential phone call with clients or other agencies regarding a client. No where one can go in office to have personal space, do a task without distraction or being uninterrupted, reflect on clinical work or debrief. Facilities are dirty, unkempt. Infestations of insects and vermin. Air con frequently inadequate.

Having predominately had individual rooms (therapy use \& office space) now having 2 other people makes it confined, noisy, no privacy, no silence to think!

The cramped, noisy work space makes it very difficult, if not impossible, to focus, to think clearly \& hinders productivity \& clear thinking \& not great for clinicians! Stress levels increase when people are in too close proximity - this is definitely the case for staff at my workplace. We need sound dividers at the very least! Aircon NEVER works consistently \& causes discomfort... some spaces are like saunas while others are icy!

It is cramped. There is no privacy at all. There is no storage for items we need such as group materials. Carpets and walls are dirty. Ceilings leak... whiteboards in all therapy rooms \& offices need to be replaced. Computers are slow \& outdated. Noise, when on the phone confidentiality to clients as there are 3-5 ppl in a room all conversations are heard by a room full of people. It is difficult to hear when there are 2-3 people in an office meant for one person. TOILETS - this as a MAJOR problem - they are dirty... we have 2 toilets for $46+$ staff often there is not one available. This is a problem for female staff. One toilet has no ventilation. Water floods through skylights when it rains.

Dirty. Cleaning not done properly. Carpets stained. Gets infested (i.e., ants, millipedes). Dark. Aircon never work properly. Noisy. Overcrowded. Unpleasant to work in. Generally atrocious.

Shared office space. Clear division in staff - some ppl work very hard (all female). ALL males don't appear to work very hard including psychotherapist - this causes lots of work stress.

Office space is allocated with no equity. Almost all women are sharing offices and all men have their own office. Also, the people who are seeing the most clients do not have their own room whereas people with smaller client loads have their own room.

Shared office - sometimes lack of privacy, etc

Shared office space has placed our therapeutic work into the category of desk office workers rather than understanding the fundamentals of therapy. It is all about saving dollars rather than the bigger picture of assisting clients to change their behaviour, emotions, etc.

Too small, confidentiality breaches, plus becomes very hot in summer, and very cold in winter, air con regularly breaks. Oven past 10 years.

While there are issues of noise and privacy... clinicians generally are respectful of other's work space

Some benefits of increased communication amongst staff, opportunity to discuss work (i.e. informal peer supervision) and at times commraderie between staff. However, shared office space is largely extremely disruptive and distracting especially when a high amount of work requires a degree of confidentiality.

Overcrowded. noisy. no power points at desk level. cluttered. inconsistent temperature management. toilet facilities needing updating.

More toilets - There is one toilet!

Cramped. No privacy. Constant noise in background from other staff talking on phone or with colleagues making it difficult for me to concentrate on triage calls.

Woefully inadequate. Interfere to a large degree to the performance of peoples' jobs

Shared space, sometimes difficult to have phone conversations. 2 locked doors to access printers.

Table 9. Comments provided by therapists occupying shared offices, about therapy space. 
It would be good to have therapy rooms that are "adolescent friendly" and 2 dedicated play therapy rooms. It is less than desirable to try to combine these age groups in the same facilities. Play therapy rooms need to have sand trays and well stored array of play therapy materials. We have an office to a window and formerly had microphone/recording equipment to use for family therapy/reflective team work due to pressure on therapy space we are no longer to book this for this purpose, although the team has identified the need for a family therapy team.

They are too small for families and resources are geared at young children and most of our clients are teenagers. In the past when working with people with mental health issues I have had my own room and much prefer this however have worked in other environments sharing interview rooms and it has been an easier process.

Not enough therapy rooms for the volume of clients \& number of staff. Most therapy rooms insects often invade the walls. Dirty - i.e., carpets dirty, walls are dirty - the cleaner rarely vacuums the floors (including the toilets) unless asked. Air con frequently inadequate thus making it uncomfortable.

Therapy rooms are untidy - Toys are meant for younger patients - not adolescents. Carpets stained. Not the same room each time - walls need painting and pictures. Just old and tired rooms.

No consistency across therapy rooms - which is definitely NOT ideal for children \& young people. I am used to being able to provide consistency of environment, space $\&$ features/toys - which is important therapeutically. We can not ensure the same room is available from session to session. Noise \& poor soundproofing is a problem. Dirty carpets, scuffed, marked walls \& paintwork - so disrespectful to clients! Cluttered, too many toys with lack of storage space.

Two therapy rooms are not sound-proofed \& they are very cramped. It is possible to actually hear the conversation in the other room. There is no storage for toys in the building or rooms and consequently the rooms look like toy shops! The carpets are dirty. We have a rodent problem, an ant infestation and now a centipede invasion as well. Therapy room walls are dirty. There are no phones, no clocks. Windows are actually barred, often graffiti is on these at the back of the building. The toilet in the corridor by the therapy room smells \& this wafts into one of the therapy rooms. One room has a permanent leak when it rains.

Not cleaned properly, carpets stained. Not appropriately resourced for teenagers... can hear conversations in corridor.

Too many clinicians sharing limited space.

It is disruptive needing to compete for therapy space with other clinicians. The rooms are not at all soundproof and this is not appropriate.

I don't have one... I have to use different rooms... sometimes hard to find a room.

Not enough therapy rooms (4 currently). Psychiatrists should only have a designated office not therapy room/office facility! Sound proofing, appropriate toys and chairs etc required. Clients frequently say to me as we walk to a therapy rooms "Oh! What room are we in today!"

Far too small. Not client (adolescent) focused. Confidentiality breaches.

Therapy rooms are well set-up \& was done with a lot of forward planning $\&$ dedication from the clinicians themselves. Comfort can be increased with appropriate furniture which is more child or adolescent friendly e.g. couches, fresh decor and other furnishings. Privacy can be increased by use of sound proof walls.

Not enough therapy rooms. Unable to see clients when not enough room.

It is difficult to share therapy rooms... It means you have to work certain days (if part-time) which is tricky with childcare in order to have a room available.

Completely inadequate. No privacy. No soundproofing. Constant noise and distraction outside. Chairs/furniture old. Paint horrible.

Poor soundproofing. 